This item was submitted to Loughborough's Research Repository by the author.

Items in Figshare are protected by copyright, with all rights reserved, unless otherwise indicated.

\title{
Companions' dilemma of intervention when they mediate between patients with intellectual disabilities and health staff
}

PLEASE CITE THE PUBLISHED VERSION

https://doi.org/10.1016/j.pec.2019.05.020

\section{PUBLISHER}

(C) Elsevier

\section{VERSION}

AM (Accepted Manuscript)

\section{PUBLISHER STATEMENT}

This paper was accepted for publication in the journal Patient Education and Counseling and the definitive published version is available at https://doi.org/10.1016/j.pec.2019.05.020.

\section{LICENCE}

CC BY-NC-ND 4.0

\section{REPOSITORY RECORD}

Antaki, Charles, and Deborah Chinn. 2019. "Companions' Dilemma of Intervention When They Mediate Between Patients with Intellectual Disabilities and Health Staff”. Loughborough University. https://hdl.handle.net/2134/37849. 
Companions' dilemma of intervention when they mediate between patients with

intellectual disabilities and health staff

Accepted for publication in Patient Education and Counselling, May 2019

\section{Introduction}

\subsection{Background.}

When a person with intellectual disabilities (ID) accesses a health service, they often require the aid of a companion to help communicate with the service provider. But as Mastebroek et al observe, "[i]n the ID health literature, relatively little attention is paid to exchange of information in the context of medical care" (2014, p 1979). Since then there has been a small-scale study by Mander (2016) of how health-related information is made accessible to adults with ID. It is useful and fine-grained, but is limited to the rather unusual case of an unmediated encounter between health-care professional and the person with ID. What is still missing is an examination of the (much more common) mediated consultation, with the mediator being a companion (a family member, friend, or a paid carer). That is the focus of this article. We shall be researching, for the first time, the actual words exchanged between adults with intellectual disabilities, medical practitioners and the companions who mediate between them in primary care settings, and we shall be using a methodology that avoids casting what they do into pre-given categories; we shall use Conversation Analysis to see exactly how they bring off their interaction in fine detail.

In the case we consider here, the service is an annual health-check, provided by local primary care practitioners (physicians or nurses), a service reported to be "effective in identifying previously unrecognised health needs, including life-threatening conditions" (Robertson et al, 2011, p 1009). For full effectiveness, however, the medical practitioner must solicit information from the patient about their symptoms and lifestyle. But the patient is not always able to understand the question, or give a full answer, and the companion mediates. We want to know how.

\subsection{Answering questions directed at the patient}

We are focussing here on what happens when the medical practitioner asks the patient a question, and the companion intervenes in the provision of the answer. This is different from the kind of "brokering" that has attracted much interest in the literature on third parties in medical consultation, which have generally focussed on linguistic interpreters (be they professionals, or family members). In the case we consider here, the companion is not translating the doctor's questions (or advice and so on), as a matter of linguistic (see Krystallidou and Pype, 2018, for a recent example) or broader "cultural" translation or brokering (e.g. C. Raymond, 2014) . Brisset et al 2013 give a useful a systematic review of such translation, but the point to note is that it deals with the explanation of the medical practitioner or the patient's words and their meaning. What we are interested in here, rather, is the companion; and specifically the companion as intervener: how they manage the task of taking a forward step when the medical practitioner has asked the patient a question, but has not received (or in some cases before they have received) an adequate answer. 


\subsection{Epistemic entitlements}

The asymmetry between companion and patient with ID is perhaps not quite the same as between a parent and a child. Certainly there the parent is very largely in command: as Strong in his classic Ceremony of the Clinic (1979, reissued 2018), observes: "It was the parents who owned, managed and worried about their children's future; and it was to them that talk was normally addressed" (2018, p 9). The situation seems to have been much unchanged when Tates et al surveyed the scene some 20 years later: "[p]arents obviously regard matters of the child's health as their own responsibility and, therefore, they usually treat their children in medical interviews as if they were absent" (Tates et al, 2002, p 115), an observation given yet more interactional evidence in Stivers (2012). Their authority consists in a complex combination of socially-sanctioned rights and entitlements as parents over young children; not all those rights and entitlements will transfer to adult children, and will be most lacking, of course, when the patient is no relation at all. But perhaps more fundamentally, what makes the relation of companion to adult patient with ID different from parent to child (or indeed linguistic interpreter to client) has to do with the policy and organisational context-factors 'outside' the actual interaction that help us understand and make sense of what is going on, and which are as it were structurally distinct. The difference is the pervasiveness of a service ideology requiring people with intellectual disabilities to be autonomous and to speak up on their own behalf, and for services to facilitate that - a structural weight of expectation that doesn't obtain for parents qua parents, or most formal interpreters, or not in the same way (for example, police and courtroom interpreters are working to what is, at least nominally, a policy of strict neutrality).

What does survive as a difference between the two parties facing the practitioner is the asymmetry, by definition, in cognitive capacity. Whatever the companion may know about the patient (by dint of their better ability to process and remember the details of their lives) the patient must know it more personally, by definition. In speaking for the patient, the companion is treading on sensitive ground. The patient has rights - epistemic rights - over their personal, private life, including much that might be relevant to a medical consultation. According to Heritage's analysis (Heritage, 2012a) a speaker's epistemic status is granted them by a range of factors which can be called on to invoke authority vis-a-vis a given listener: their expertise, experience, position in a hierarchy, institutional privileges, and so on. If the patient is a child, their parent, for example, in principle has epistemic entitlement to describe their child's symptoms, by dint of the parent's greater capacity of understanding, as well as any socially-approved authority.

On the other hand, a person may claim an epistemic stance on some information in the way they express themselves - "through the design of turns at talk" (Heritage, 2012, p.33) whatever their actual expertise and cognitive advantages. So even a parent who knows the facts of the matter may, for example, downplay their expertise, take a not-knowing stance, and invite their child to "remember" how high their temperature had been the day before. That is to say that any companion can defer to the patient's greater entitlement, whether or not it is well-founded. The situation of a person with an intellectual disability is the same as the child, or any other person: whether or not they actually know the answer to the medical practitioner's question, they can be treated as having it, or not. How the companion brings this off - whether they manage what Nilsson et al (2018), in studying companions helping a person with dementia tell a story, call "joint speakership", or whether they merely take 
over, as Tates et al (2002) suggest, is a matter of discovery, and the key to it is the degree of epistemic authority the companion is willing to display.

1.4 Aim

So in the cases we shall be considering here, we need to keep an eye out for how the companion designs their talk - how they manage their claim to know information over which the patient has prior rights of entitlement. Do they use their greater epistemic status to simply over-ride the patient, or do they adopt different epistemic stances to manage the matter with more delicacy?

\section{Material and Methods}

2.1 Data collection took place between July 2016 and June 2017 in GP practices across London. Practices were eligible if they were taking part in a national incentivized scheme to complete annual health checks with patients registered as having intellectual disabilities (Slowie \& Martin, 2014), and had conducted at least 5 health checks during the last reporting period. An initial invitation to take part in the study was made by practice staff to patients with intellectual disabilities who were over 18 and did not need support from an interpreter. A researcher followed up with a home visit to complete consent procedures, including recruiting research 'consultees' for patients deemed unable to give informed consent regarding their participation (Department of Constitutional Affairs, 2007). Ethical approval was given by an NHS Research Ethics Committee (Ref:16/LO/0455).

Altogether 33 health checks were video-recorded, conducted by 14 practitioners from $10 \mathrm{GP}$ practices. Four (29\%) of the practitioners were practice nurses, the others were doctors and one physician associate. Two doctors conducted health checks in the patients' care home, others took place in the GP surgery. The video camera was set up by the researcher who left the room before the health check started. Most patients ( $n=29,82 \%)$ attended accompanied by a family member $(n=9)$ and/or at least one paid carer or supporter $(n=23)$; of these, 4 had a non-speaking patient, leaving 25 that are useable for the purposes of the analysis.

2.2 We analysed the data with the apparatus of Conversation Analysis (CA), an approach which combines close inspection of video data with a body of established findings about the workings of conversation - how the detailed placement and design of turns at talk perform actions. For a wide-ranging collection of authoritative accounts of the scope of CA, see Sidnell and Stivers (2012), for its application to a range of medical and other institutional interactions, see Maynard and Heritage (2005) and Antaki (2011), and for its particular applicability to doctor-patient consultations, see Drew et al (2001). CA has been usefully applied to interactions involving people with ID since the pioneering work of Yearley and Brewer (1989), with an acceleration of interest in the last ten years: see, for example, the work on how people with ID are offered choices (Antaki et al, 2009), or how they engage others in conversation (Antaki et al, 2016); how staff pursue answers from them (Finlay and Antaki, 2012); and, in a sustained analysis of their interactions with service-providers, Williams (2011). Following the conventions of CA, we report the video data in the form of transcriptions; for a glossary of their notation, please see the Appendix. 


\subsection{Cases left out of analysis}

We are leaving aside two broad classes of companion's participation in the consultation which imply knowledge of the patient, but are not answers to the medical practitioner's questions. One class is their replies to questions directed specifically at the companion themselves (and not at the patient), and the other is their replies to questions asked them by the patient. We also leave aside the occasions on which the companion initiates some business directly with the medical practitioner - for example, describing the patient's current medication, asking about appointments, and so on. In other words, we shall be examining only those cases where the patient has been asked a question about themselves, and the companion intervenes.

\section{Results}

3.1 Cases considered: companions' interventions when the question is directed to the patient When the medical practitioner directed a question to the patient, we found four broad kinds of intervention by the companion which involved some kind of claim to know information which would be, in typical circumstances, in the domain of the patient. To use the terminology from Heritage and Raymond (2005), this is information to which the patient has greater epistemic entitlement: it is knowledge about the details of their lives, and indeed sometimes their feelings and beliefs.

We set these out as a gradient:

a) hinting at relevant information which the patient knows, but has not yet revealed

b) elaborating/clarifying the patient's answer to better fit the medical practitioner's requirements

c) repairing/correcting the patient's answer to better fit the medical practitioner's requirements

d) bypassing the patient, to self-select as the recipient of the medical practitioner's question to the patient, in exact overlap with, in advance of, or after lapsed, turn from the patient

The interventions we discovered seemed to form a gradient of claimed entitlement, from least to most - as we have set them out in the list above. At the end of least entitlement, the companion defers to the patient by only offering some hint or clue to allow them to generate the answer themselves. At the most entitled end of the spectrum, they step in to answer the question themselves. The gradient moves from the companion displaying the least to the most entitlement to show that they know better, or know more, than the patient does - as Brown and Levinson (1987) would describe it, a gradient of "impositive cost". Figure 1 shows the gradient graphically.

[Figure 1 about here]

Figure 1: Interventions showing companions' epistemic stance vis à vis the patient

In what follows we document these interventions, and show that they are, necessarily, always a matter of the companion making a judgement between encroaching on the patient's epistemic rights - their entitlement to report the details of their own lives - and progressing the medical objectives of the interaction. 
3.1.1 Hinting and prompting: Minimal assertion of epistemic authority by deferral to the patient's priority.

We begin at the least presumptive end of the gradient of entitlement.

In these cases, the companion defers to the patient's epistemic priority by a variety of hints or prompts. Although these hints and prompts must imply that the companion themselves already has the information, soliciting it this way displays the companion's knowledge only minimally, and gives the patient the opportunity to provide the information as if at first hand.

These cases arise when patient has been asked a question by the medical practitioner and has either provided no answer, or has provided one that is deemed by the companion to be incomplete. The companion uses a variety of techniques to induce the patient to either volunteer an answer, or a fuller answer, or to assent to the information implied in the companion's turn.

In Example 1 below, the medical practitioner has asked the patient Cliff about his mobility, selecting him explicitly, by gaze direction and body orientation. He answers by giving a long exposition of the guidance he's received from the occupational therapist. We join as he reaches the end.

[Example 1 about here]

The patient's answer, especially "So far it's been going good", line 568, is receipted by the doctor as a self-assessment in third position (Schegloff, 2007) completing his report. But it seems to prompt his companion Louis to issue a hint that in fact the patient nevertheless does "find it hard sometimes" (line 571). Notice the careful work done by the companion to intervene only after the patient has fully completed his turn and the action for which it is the vehicle (that is, an assessment of his current position (so far t'ch wood... 's bin going good.). The companion is the careful to defer to the patient's own expressed report (cf. Holt, 2000) of difficulty ("you told me this morning"), and the further evidence of the patient wanting an "oh tee" (OT, occupational therapist) on the basis of that difficulty. The companion does protect his turn by rushing-through his account of what the patient said (see Schegloff, 1982 on speeding up talk in "rush-throughs"). Nevertheless, by alluding to the patient's own expressed views, the companion minimises their epistemic status and defers to the patient's prior claim to the information.

3.1.2 Expansion and clarification: greater encroachment, but maintaining deference to the patient

In these cases, unlike the hints above, the companion presumes more direct knowledge of the patient's circumstances, by giving, in their own voice, a clarification or expansion of the patient's answer. Although the source of the information is now clearly the companion, nevertheless the integrity of what the patient had said, and its relevance to the medical practitioner's question, is not directly challenged. In Example 2 below, the doctor asks the 
patient Jeanie a polar about earwax; the patient's turn in response (line 285) is not formatted as a yes/ no, and is hard to see as an intelligible answer. Her companion volunteers a candidate answer, and at 289 and 291 casts that candidate as one requiring confirmation from the patient (addressed by name, a further form of explicit recipient design). What we focus on here is that subsequently happens whether doctor issues a follow-up question at line 294.

[Example 2 about here]

The companion's intervention at line 296 is prefaced by an on-the-record explicit agreement with the patient, establishing her at-least-equal rights in the matter ${ }^{1}$; then offers a tentative ("I think...") version of the possible time period that was implied by the patient's answer (the summer); then offers an alternative period. One way or another, the companion's answers are more attuned to the kind of evidentially-supported estimation of time that is more likely to be appropriate to the medical agenda - and, in that sense, superior to the patient's estimate of "longer". The design of her turns are what Heritage and Raymond (2005) would term epistemically inferior or at least as no more than equally knowing. She maintain the integrity of the patient's answer, while offering expansions from a position of low, or lesser, entitlement.

In Example 3 below, the medical practitioner has asked patient Phil about his leisure, and he has answered in terms of supporting a football team.

[Example 3 about here]

In this zone of the spectrum, where the companion expands and clarifies the patient's answer, there is a variant: the companion may add the information beyond the apparent needs of the required information, and is an initiation inserted into the interaction after the question-answer sequence has been apparently satisfactorily completed. Still, as in the other case here, the patient's answer is not gainsaid; it retains its integrity, but now the companion takes a further initiative in providing deeper background, distant from the required information. At line 113 the companion expands her own version of his habits with an increment (Schegloff 2007) ending with a tag question plus laughter particles. As Heritage and Raymond argue, the force of a tag question is its apparent concession to the other party: the questioner "formulates [their] turn as... a question to be answered rather than as an assertion to be agreed with; thus [they] cede epistemic authority in the matter to [their] coparticipant" (Heritage and Raymond, 2005 p 20). So the companion's tag implies that the source of the information about the cake and tea is the patient himself. Perhaps this comparatively respectful formulation (pace Hepburn and Potter, 2011, who have a darker analysis of tag questions) helps palliate the presumptuousness of the companion's intervention

\footnotetext{
${ }^{1}$ But not her prior right, which would have been signalled by a news receipt like "oh" and so on - see Heritage (1984), and the further treatment in Heritage and Raymond, (2008)
} 
The two cases below show this move toward the more intrusive end of the gradient. In Example 4, at line 39 the nurse has resolved the reason for Barbara's visit to the surgery ("cos you needed the certificate"). Barbara gives minimal acknowledgement of this at line 41 , and at this point the companion Ilaria self-selects to announce further - apparently irrelevant - information, unbidden (she was happy it was a man). It has an overtone of implying that the patient was sexually interested in the doctor, but note that the nurse after an initial arch "ooh", markedly offers a different candidate explanation - he was a new face, relieving the patient of reacting to what may have been an over-intimate revelation. In the subsequent example (5), patient Christina has answered in the affirmative about her general well-being (after questions about her sleeping, not shown); at that point the companion Sophia self-selects to offer a report about Christina's inner life, again, apparently without apparent warrant from the current conversational trajectory (line 202).

[Examples 4 and 5 about here]

The companions' contributions don't offer strictly relevant information unless they are meant to evidence the companion's intimate knowledge of the patient (and thus bolster their epistemic status more generally). What differentiates them in structural terms from the previous ones in this section is that the companions self-select to issue their turn, when the action underway is, ostensibly, over and done with. That signals a move towards the still more entitled zone of the spectrum, where the companion becomes more assertive in their offering of information.

\subsubsection{Beyond expansion or qualification, and into correction}

Now the companion encroaches farther into the patient's epistemic territory by not merely adding to, or clarifying, what was said, but qualifying it to the point of outright contradiction. In Example 6 below, the companion's new information casts doubt on what is familiar from Grice (1989) as the maxim of quantity - that the patient has said all that needs to be said.

\section{[Example 6 about here]}

The patient David has been asked about his fitness on a treadmill, and in lines 394-395 gives a comparatively positive account; when the medical practitioner checks (line 396-7), he confirms that he has not had to stop to draw breath. At this point the companion selfselects to issue a disjunctive (and, therefore, disaffiliative - see Steensig, 2012) qualification. That corrects the patient not by outright rebuttal, but by revealing an aspect which, when known, puts the information about his fitness in a less positive different light.

In the next example there is a still more direct correction of the adequacy of the patient's account:

[Example 7 about here]

Patient Cliff is describing positively his visit to the opticians. This is received with positive acknowledgements by the medical practitioner (line 1239 and 1242). At this point the 
companion self-selects (line 1243) to issue a bald contradiction of Cliff's account of the visit, pointing to a mistake on the optician's part.

\subsubsection{Bypassing the patient: taking unilateral epistemic control by directly answering the medical practitioner's question}

We have now reached the point at which the companion displays the greatest entitlement to display their epistemic authority over the patient's circumstances. Here the companion answers the medical practitioner's question themselves, either in perfect overlap with the onset of the patient's turn or, in the clear. We give two short examples together to illustrate the practice.

[Examples 8 and 9 about here]

In each case, the medical practitioner has directed their question (and their gaze, as the video shows) at the patient, yet it is the companion who offers an answer; and in each case, the answer is about something about which the patient would typically be thought to have the greater entitlement to know - because it is a matter of preference or internal effort. In both cases, the patient exhibits no reaction to the intrusion by the companion - there is no change in their gaze, facial expression or body orientation.

\section{Resistance}

We should note that on a very few occasions, patients did register their resistance to their companion's intervention. These tended to be mute, and therefor ambiguous. One example is a case where the companion issues what might be seen as overly intimate, and unnecessary, information.

[Example 10 about here]

At the start, all seems to flow smoothly, though even here the nurse invites some sort of contribution from the companion. Although nurse certainly orients to the patient at the start of her question line 451, but right at the end does a brief eye-flick to the companion; nevertheless the patient selects herself to answer. The same happens again at turn-initial and turn-terminal position in line 457, and this perhaps licences the companion to respond; (but she does show sensitivity to the patient by waiting for 0.5 of a second before selfselecting, in overlap with the patient). At 462 the nurse directs her question unambiguously to the companion, who after a 0.6 second delay answers. Her oh-yes prefaced response on the patient's behalf at line 464 is a quite strong claim to epistemic priority (see Heritage, 1984 on "oh" as responses to news announcements). Notice also the companion's use of the terminal tag-question don't you; it looks like an orientation to the patient's contribution to the production the information, but, like the tag question in Example 2, if we follow the analysis of Heritage and Raymond (2005), it constructs that contribution as a matter of agreement with the companion rather than as an independent source of the information.

[Figure for Example 10 about here] 
So by line 467 both the companion and the patient have answered the question adequately, and the patient has confirmed it (if minimally). What then, do we make of the increment sometimes twice offered by the companion in line 469 ? Possibly it is an intrusion too far into the details of the patient's bowel movements; perhaps that is what the patient's arm-raise signifies, blocking the companion out at the moment when her response has been heard to start (the patient does raise her hands at other points in the interaction, but usually only to adjust her glasses, and not to occlude her face). And perhaps that is what motivates the companion to extend her turn with laughter particles, to signal her acknowledgement that she may have gone too far.

Those must remain speculations. In the example below, the patient's resistance is clearer. We join as companion Vicky offers a direct answer (line 718) to the doctor in the absence of a reply from her son, patient Sam. She then moves to the most impositive end of the spectrum by scolding him for not speaking (lines 722-725).

[Example 11 about here]

This consultation was one in which the patient and companion chose to be audio-recorded only, so we only see the doctor; she is in full view, looking towards the patient and companion, to one side of, and behind, the camera. Her expression throughout the exchange is smiling and could be glossed as 'encouragingly amused'; it may be that this optimistic visible reception of the patient's first answer is enough to licence what the mother says (although not delivered in "smile voice") as somehow affectionate, perhaps 'teasing'. One way or another, though, the companion has penetrated deep into her son's epistemic territory, claiming to know not only that he can speak very well, but that he does so only when he chooses. Sam's "oh be quiet Mummy" at line 729 is the most direct form of resistance in our data. But it is rare.

\section{Discussion and Conclusion}

\section{Discussion}

We set out in this article to identify how companions mediated between a medical practitioner and a patient who had an intellectual disability. We found that, in our sample, companions of intellectually impaired patients generally did not act as parents are reported, by Tates et al, to act vis-à-vis their children: "[p]arents obviously regard matters of the child's health as their own responsibility and, therefore, they usually treat their children in medical interviews as if they were absent" (Tates et al, 2002, p 115). Far from it; most answers directed at the patient were answered by the patient. On occasion, though, the companion did intervene; but when they did, perhaps mindful of the dangers of what has been called "epistemic injustice" (Carel and Kidd, 2014), they did so in a carefully calibrated manner, on a gradient of lesser or greater epistemic authority, from hinting to outright preemptive intercession.

One way of interpreting the findings is as a matter of the companion choosing how to solve the dilemma of encroaching on the patient's prior entitlement to know their own circumstances, versus hindering the objectives of the medical encounter. On the one hand, 
to provide an explicit answer to the medical practitioner's question, when it has been asked of the patient, is to presume the patient's fundamental incompetence to know their own lives; but to leave the information unspoken, or the faulty answer uncorrected, fails to satisfy the medical practitioner's question and so vitiates the point of the health check.

\subsection{Conclusion}

The gradient of intervention we discovered describes the various levels of presumption the companion is willing to make. By choosing an intervention at the lower, less entitled end of the spectrum, the companion offers the patient the chance to give the required information as if at first hand. The other end is nakedly imposing.

As mentioned in the Introduction, this falls along the gradient of what Brown and Levinson (1987) classically called the gradient of "impositive cost". In Heritage's (2016) reading of Brown and Levinson (reading from most imposing to least) "across this cline... Self is less and and less obliged to risk positive face by going on record, constraints on Other are progressively reduced, and co-operation is progressively distilled into an ever more purified

... form of co-ordination" (2016 p 28). At that end, the recruiter's (or in our case, the companion's) merest hint works to produce the desired outcome. In our data, the pivot around which all this swings, of course, is the patient's standing status as intellectually disabled. If the companion wants to preserve the patient's fundamental epistemic rights as a person, they still have to act as if the patient has the answer to the doctor's question whether they do or not. There are many factors which will be at play to move the companion up and down the gradient; one which promises useful new research is the nature of the relationship between patient and companion - do parents, for example, have greater right to transgress at the more impositive end of the scale than do paid carers? Does the degree of intellectual impairment make a difference (as of course, in the case of the profoundly impaired, it must)?. These are questions for the future.

\subsection{Practice Implications}

Unlike previous studies, which have suggested a dichotomous classification of companions' interventions into, for instance 'autonomy enhancing' and 'autonomy detracting' (Wolff et al., 2017), this study provides practitioners with more granular and detailed examples of how companions themselves carefully manage issues of epistemic rights and responsibilities within triadic consultations. This contributes to ongoing refinement of what 'autonomy' might mean for people with significant support needs, as our findings reinforce contemporary conceptualisations of autonomy as relational and enacted through unfolding interactions (Williams et al 2019). However, negotiation of speaking rights and roles for patients with ID and their companions (talk about talk) is seldom introduced by practitioners as a topic meriting discussion within the health consultation and our CA analysis illustrates the risks to patient self-determination when consideration of these power dynamics is overlooked. We would therefore encourage practitioners to initiate a respectful conversation regarding their expectations of companions' role in interaction as a preliminary to effective communication when people with ID attend health appointments with a companion (Laidsaar-Powell, Butow, Boyle, \& Juraskova, 2018).

\section{References}


Antaki, C, Crompton, RJ, Walton, C, Finlay, WML (2016) How adults with a profound intellectual disability engage others in interaction, Sociology of Health and IIIness: a journal of medical sociology, 39, 581-598

Antaki, C, Finlay, WML, and Walton, C. (2009) Choice for people with an intellectual impairment in official discourse and in practice. Journal of Policy and Practice in Intellectual Disabilities, 6(4) 260-266

Antaki, C. (Ed.). (2011). Applied conversation analysis: Intervention and change in institutional talk. Basingstoke: Palgrave

Antaki, C., Barnes, R., \& Leudar, I. (2005). Self-disclosure as a situated interactional practice. British journal of social psychology, 44(2), 181-199.

Bolden, G. B. (2000). Toward understanding practices of medical interpreting: Interpreters' involvement in history taking. Discourse studies, 2(4), 387-419.

Brisset, C., Leanza, Y., \& Laforest, K. (2013). Working with interpreters in health care: A systematic review and meta-ethnography of qualitative studies. Patient Education and Counseling, 91(2), 131-140.

Brown, P. \& Levinson, S. C. (1987). Politeness: Some universals in language usage. Cambridge" Cambridge University Press.

Carel, H., \& Kidd, I. J. (2014). Epistemic injustice in healthcare: a philosophical analysis. Medicine, Health Care and Philosophy, 17(4), 529-540.

Department of Constitutional Affairs. (2007). Mental Capacity Act 2005 Code of Practice. London: The Stationary Office.

Drew, P., Chatwin, J., \& Collins, S. (2001). Conversation analysis: a method for research into interactions between patients and health-care professionals. Health Expectations, 4(1), 5870.

Finlay, W M L and Antaki, C. (2012) How staff pursue questions to adults with intellectual disabilities. Journal of Intellectual Disability Research, 56, 361-370

Ford, J., Hepburn, A., \& Parry, R. (2019). What do displays of empathy do in palliative care consultations?. Discourse Studies, 1461445618814030.

Grice, H.P. (1989). Studies in the Way of Words. Harvard University Press.

Heritage, J. (1984). A change-of-state token and aspects of its sequential placement. In J M Atkinson and J. Heritage (eds) Structures of social action, Cambridge: CUP, 299-345. 
Heritage, J. (2012a). The epistemic engine: Sequence organization and territories of knowledge. Research on Language \& Social Interaction, 45(1), 30-52.

Heritage, J. (2012b). Epistemics in action: Action formation and territories of knowledge. Research on Language \& Social Interaction, 45(1), 1-29.

Heritage, J., \& Raymond, G. (2005). The terms of agreement: Indexing epistemic authority Hsieh, E. (2007). Interpreters as co-diagnosticians: Overlapping roles and services between providers and interpreters. Social science \& medicine, 64(4), 924-937.

Holt, E. (2000). Reporting and reacting: Concurrent responses to reported speech. Research on Language and Social Interaction, 33(4), 425-454.

Krystallidou, D., \& Pype, P. (2018). How interpreters influence patient participation in medical consultations: The confluence of verbal and nonverbal dimensions of interpretermediated clinical communication. Patient education and counseling.

Laidsaar-Powell, R., Butow, P., Boyle, F., \& Juraskova, I. (2018). Managing challenging interactions with family caregivers in the cancer setting: Guidelines for clinicians (TRIO Guidelines-2). Patient Education and Counseling, 101(6), 983-994.

Mander, C. (2016). An investigation of the delivery of health-related accessible information for adults with learning disabilities. Tizard Learning Disability Review, 21(1), 15-23.

Mastebroek, M., Naaldenberg, J., Lagro-Janssen, A. L., \& de Valk, H. V. S. L. (2014). Health information exchange in general practice care for people with intellectual disabilities -a qualitative review of the literature. Research in developmental disabilities, 35(9), 19781987.

Maynard, D. W., \& Heritage, J. (2005). Conversation analysis, doctor-patient interaction and medical communication. Medical education, 39(4), 428-435.

Nilsson, E., Ekström, A., \& Majlesi, A. R. (2018). Speaking for and about a spouse with dementia: A matter of inclusion or exclusion?. Discourse Studies, 20(6), 770-791.

Raymond, C. W. (2014). Epistemic brokering in the interpreter-mediated medical visit: Negotiating "patient's side" and "doctor's side" knowledge. Research on Language and Social Interaction, 47(4), 426-446.

Robertson, J., Roberts, H., Emerson, E., Turner, S., \& Greig, R. (2011). The impact of health checks for people with intellectual disabilities: a systematic review of evidence. Journal of Intellectual Disability Research, 55(11), 1009-1019.

Schegloff, E. A. (1982). Discourse as an interactional achievement: Some uses of 'uh huh' and other things that come between sentences. Analyzing discourse: Text and talk, 71, 93. 
Schegloff, E. A. (2007). Sequence organization in interaction: Volume 1: A primer in conversation analysis (Vol. 1). Cambridge University Press.

Sidnell, J., \& Stivers, T. (Eds.). (2012). The handbook of conversation analysis Winchester: John Wiley \& Sons.

Slowie, D., \& Martin, G. (2014). Narrowing the health inequality gap by annual health checks for patients with intellectual disability. British Journal of General Practice, 64(619), 101-102. Steensig, J. (2012). Conversation analysis and affiliation and alignment. The encyclopaedia of applied linguistics.

Stivers, T. (2012). Physician-child interaction: When children answer physicians' questions in routine medical encounters. Patient education and counseling, 87(1), 3-9.

Strong, P. M.,. (1979/ 2018). The ceremonial order of the clinic: Parents, doctors and medical bureaucracies. Abingdon: Routledge.

Tates, K., Meeuwesen, L., Elbers, E. P. J. M., \& Bensing, J. (2002). 'I've come for his throat': roles and identities in doctor-parent-child communication. Child: care, health and development, 28(1), 109-116.

Williams, V. (2011). Disability and discourse: analysing inclusive conversation with people with intellectual disabilities. Chichester: Wiley-Blackwell.

Wolff, J. L., Guan, Y., Boyd, C. M., Vick, J., Amjad, H., Roth, D. L., ... Roter, D. L. (2017). Examining the context and helpfulness of family companion contributions to older adults' primary care visits. Patient Education and Counseling, 100(3), 487-494.

https://doi.org/10.1016/j.pec.2016.10.022 
Appendix: Transcription Symbols

\begin{tabular}{|c|c|}
\hline$()$. & Just noticeable pause \\
\hline$(.3),(2.6)$ & Examples of timed pauses, in seconds \\
\hline $\begin{aligned} \text { word } & {[\text { word }] } \\
& {[\text { word }] }\end{aligned}$ & $\begin{array}{l}\text { Square brackets aligned across adjacent lines denote the } \\
\text { start and end of overlapping talk. }\end{array}$ \\
\hline$. \mathrm{hh}, \mathrm{hh}$ & $\begin{array}{l}\text { In-breath (note the preceding full stop) and out-breath } \\
\text { respectively. }\end{array}$ \\
\hline wor- & A dash shows a sharp cut-off \\
\hline wo: $r d$ & $\begin{array}{l}\text { Colons show that the speaker has stretched the preceding } \\
\text { sound. }\end{array}$ \\
\hline (words) & A guess at what might have been said \\
\hline$(\quad)$ & Talk too unclear to merit even a guess. \\
\hline $\begin{array}{l}\text { word }= \\
\text { =word }\end{array}$ & $\begin{array}{l}\text { The equals sign shows that there is no discernible pause } \\
\text { between two speakers' turns or, if put between two sounds } \\
\text { within a single speaker's turn, shows that they run together }\end{array}$ \\
\hline word, WORD & Underlined sounds are louder, capitals louder still \\
\hline$£$ fword & Delivered in a 'smile' voice \\
\hline *word* & "Creaky" voice \\
\hline${ }^{\circ}$ word ${ }^{\circ}$ & Material between "degree signs" is quiet \\
\hline $\begin{array}{l}\text { >word word }<<\text { word } \\
\text { word }>\end{array}$ & Inwards arrows show faster speech, outward slower \\
\hline$\uparrow_{\text {word }}$ & Upward arrow shows upward intonation \\
\hline$\downarrow_{\text {word }}$ & Downward arrows shows downward intonation \\
\hline wo $(h) r d$ & (h) shows that the word has "laughter" bubbling within it \\
\hline ( (gruff voice) & $\begin{array}{l}\text { Attempt at representing something hard, or impossible, to } \\
\text { write phonetically }\end{array}$ \\
\hline$\rightarrow$ & Analyst's signal of a significant line \\
\hline
\end{tabular}




\section{$\underline{\text { Role of Funding }}$}

[Anon] has been funded by [anon]. The article presents independent research funded by [anon]. The views expressed are those of the authors and not necessarily those of [anon]. No restrictions on free access to or publication of the research data has been imposed by the funding body. 
Figures and Examples

(see also .png files sent separately)

Actions the companion takes in intervening

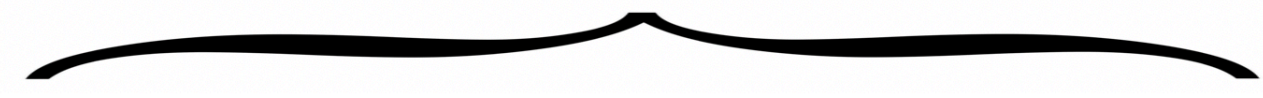

Hinting at Elaborating Correcting Bypassing the answer the answer the answer the patient

Degree to which the companion claims epistemic entitlement over the patient

Figure 1: Interventions showing companions' epistemic stance vis à vis the patient

\section{Examples}

Example 1: shopping. Pat = patient ("Cliff", Comp = paid carer.

At line 547, the Nurse orients her gaze and body to Pat.

HC7 15.06

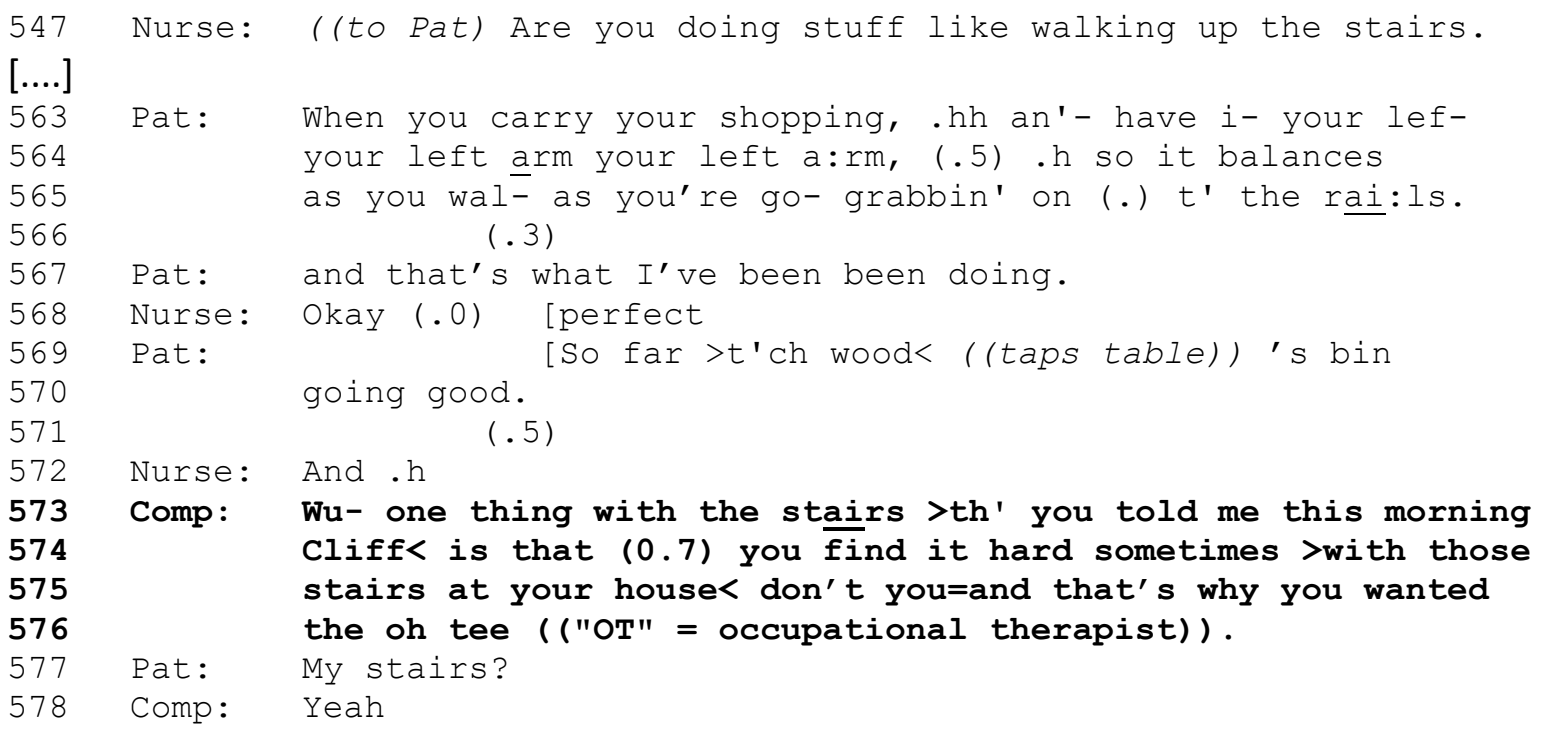

Example 2: summer. Pat = patient "Jeanie"; Comp = her mother.

Note that the configuration of the seating, with the doctor sitting side-on to the patient and companion, does not allow us to be completely sure of the target of the doctor's gaze; note, however, that wen the doctor delivers the questions in lines 284 and 294, the companion is looking towards the patient, and it is the patient who takes it that she has been selected for the next turn)

HC4 08.20

283 Dr:

((to patient) so- is there any earwax in there, d'y think, 
284

285

286

287

288

289

290

291

292

293

294

295

296

297

298

299

300
$(1.0)$

Pat: Ah she just got a $\mathrm{m}^{-}$(.) (move) m-

(.5)

Comp: It $\mathrm{w}^{\prime} \mathrm{s}^{-}>$they removed it<=But they had a look first

Pat: $\quad \mathrm{Mmm}$

Comp: Didn't they Jeanie.

Pat: Yeah

Comp: They had a look first din't they.

Pat yeah, they did have ( $t-a)$ look.

Com:p: yeah $\left[^{\circ}\right.$ (they had a look at that) ${ }^{\circ}$

Dr: [Was that recently, or a long (.) er while ago.

Pat: $\quad$ Er (.) longer

Comp: Yeah you're right 'Jeanie yeah ${ }^{\circ}$ I think it was over summer [or

Dr: $\quad$ [Yeah okay,

Comp: Or it could've been the beginning of the year, ${ }^{\circ} I$ don't remember ${ }^{\circ}$

Example 3: soaps. Pat $=$ patient ("Phil"); Comp $=$ his mother. Pat has been talking about football.

HC11 2.45

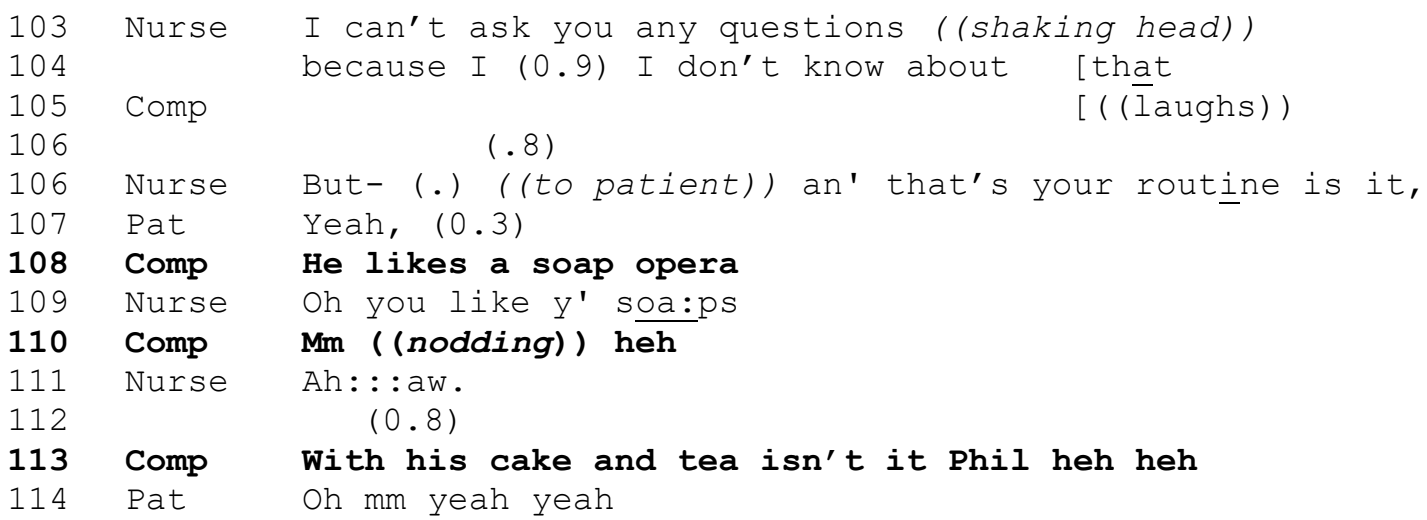

Example 4: a man. Pat $=$ patient; Comp $=$ her mother

HC15 1.55

35 Nurse: He's a nice doctor isn't [he

36 Pat: [Yeah I know yes

37 Nurse: Yes

Pat: This reason now because I came to- (.4) see him.

Nurse: Yeah 'cos you needed a (.3) <certificate>.

Pat: $\quad[\mathrm{Hm}$

Comp: [She was happy it was a ma:n

$(.5)$

Nurse: $0:::$ h (("appreciative" voicing))

Comp: Yeah

Nurse: New face.

Pat: (nods))

Nurse: Had you met him befo:re,

Pat: ((nods)) this's m'first time. 
Example 5: Father Christmas. Pat $=$ patient Comp $=$ her mother

HC13A 12.00

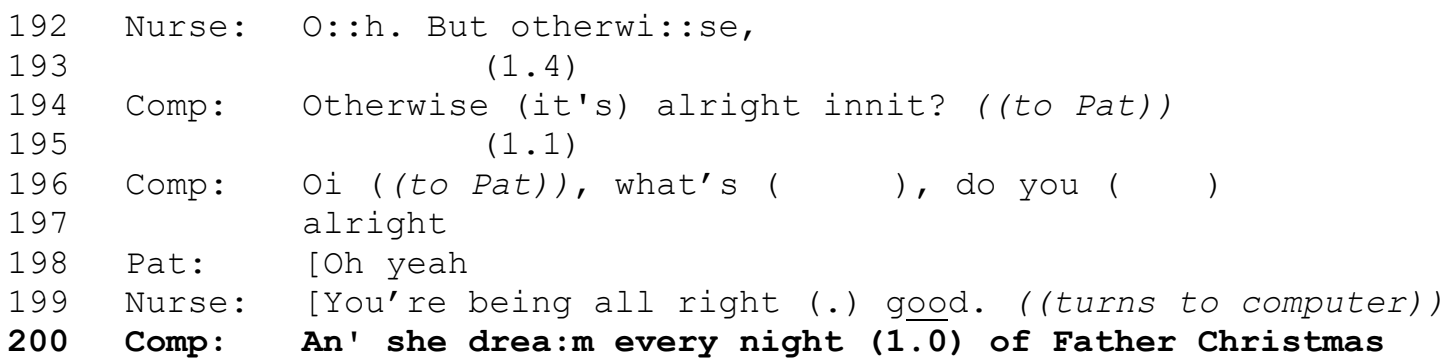

Example 6: treadmill. Pat $=$ patient; Comp $=$ paid carer HC10 12.25

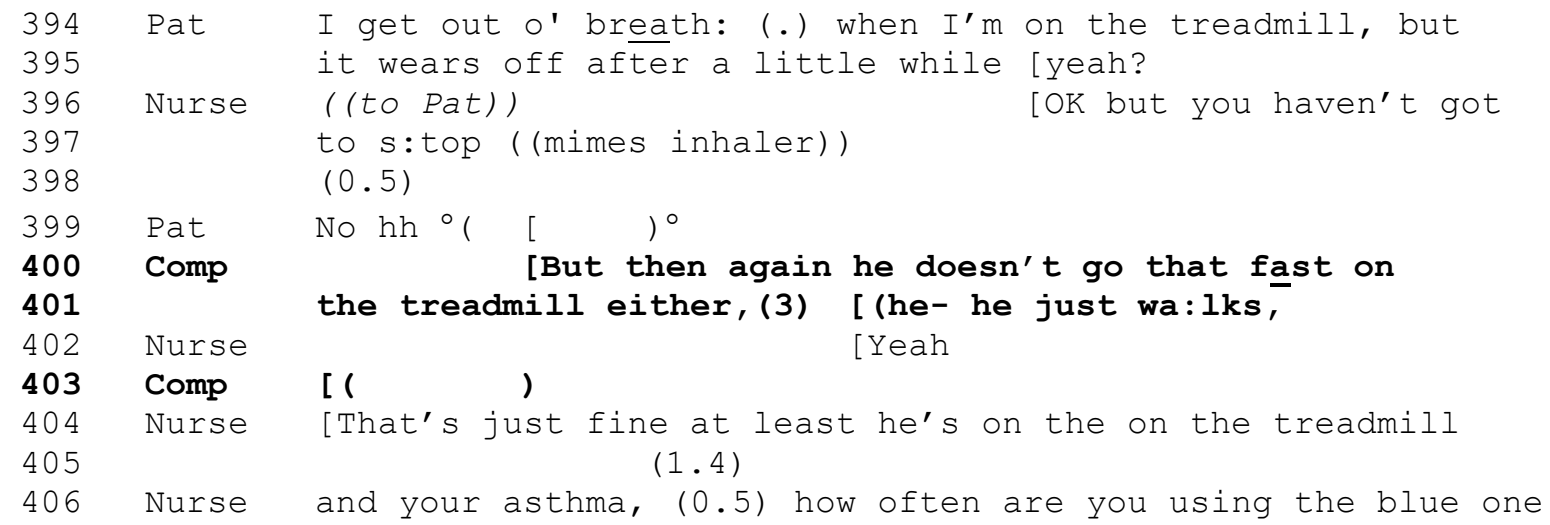

Example 7: optician. Pat $=$ patient Comp $=$ paid carer HC7 33.25

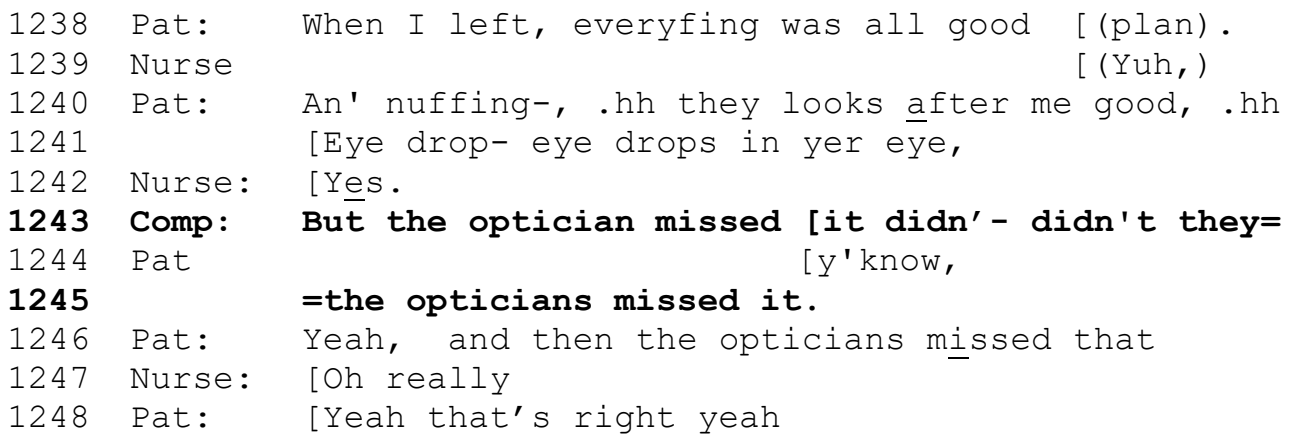

Example 8: kilograms. Comp = patient's mother Mother is doing up patient's cuff; both are looking down

HC5 20.40

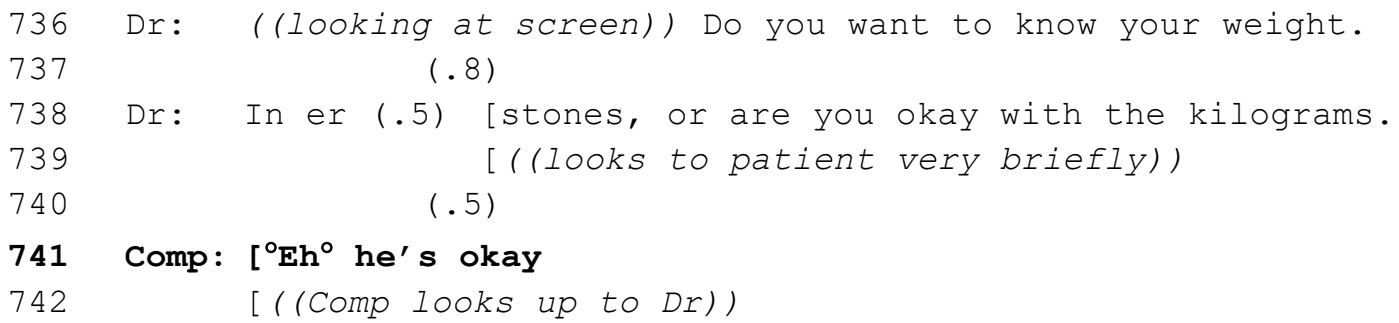




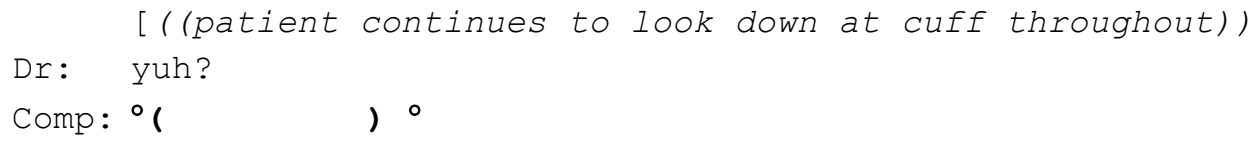

Example 9: heart. Pat $=$ patient; Comp $=$ her mother

HC15 5.20 ((Nurse's gaze and body orientation shows that all her questions in this extract are directed to the patient))

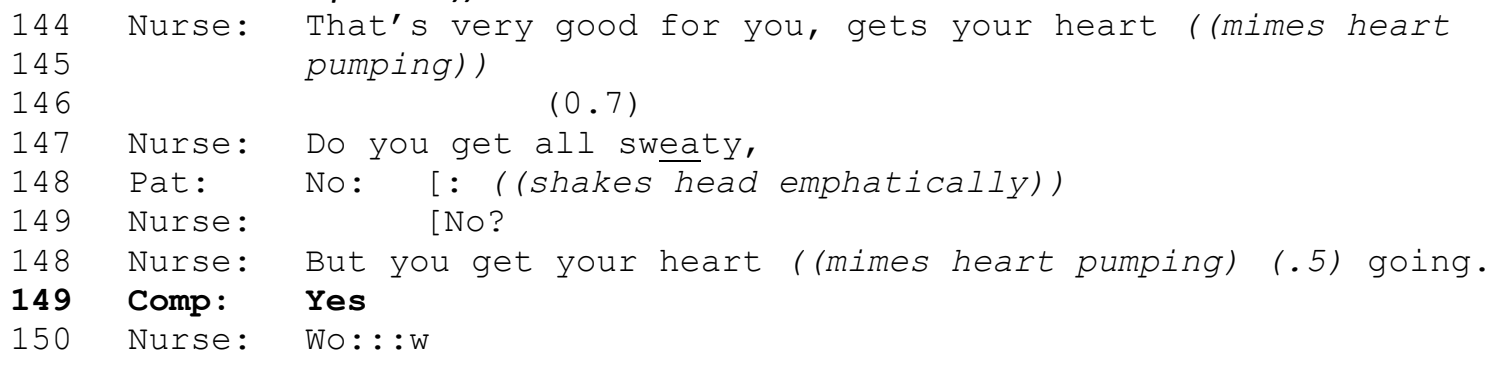

Example 10: bowels. Pat $=$ patient; Comp:= her mother

HC25 13.35

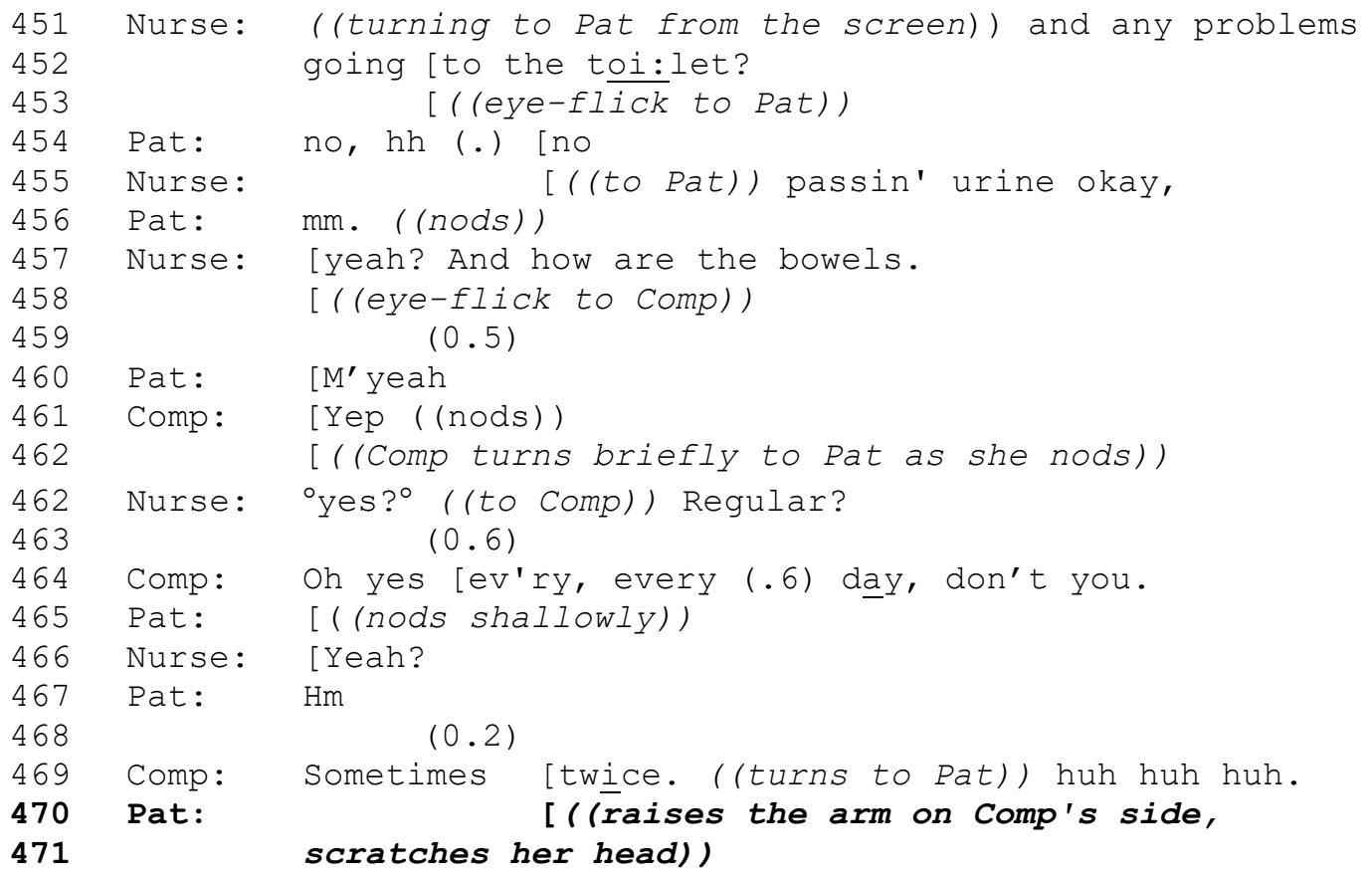

Example 11: be quiet. Pat $=$ patient Comp $=$ his mother HC33 15.50

[Note that throughout the exchange, the patient and companion are to one side of, and slightly behind, the camera; the doctor is clearly visible]

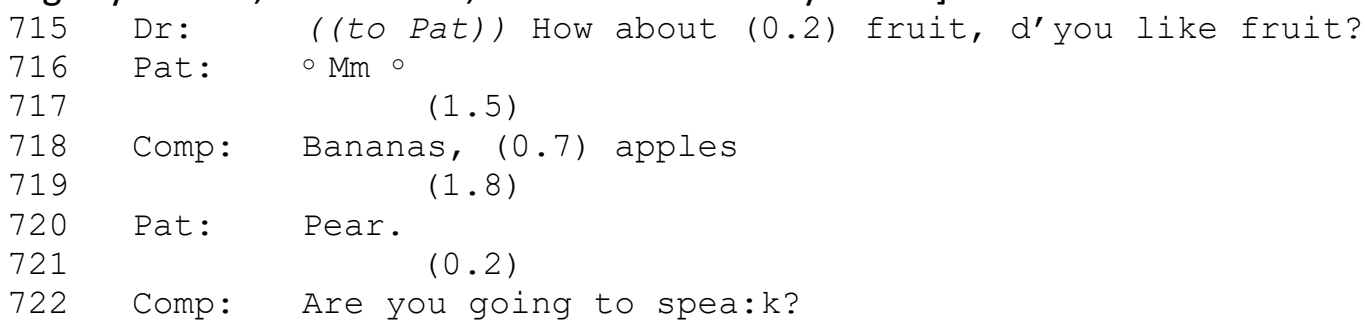


723 724

725

726

727

728

729
Pat: No.

Comp: Cause you can speak very well (0.2) when you feel like it.

Pat: $\quad H m m$

Pat: Oh be quiet Mummy. 